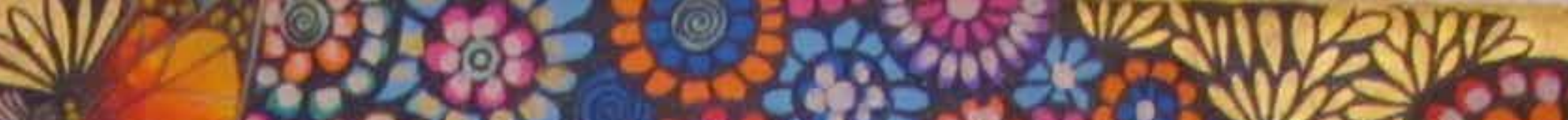

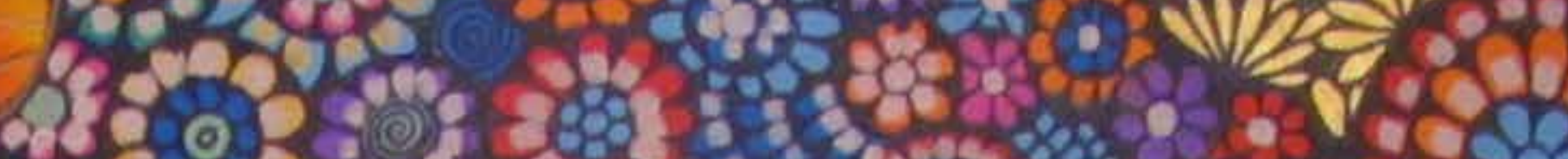

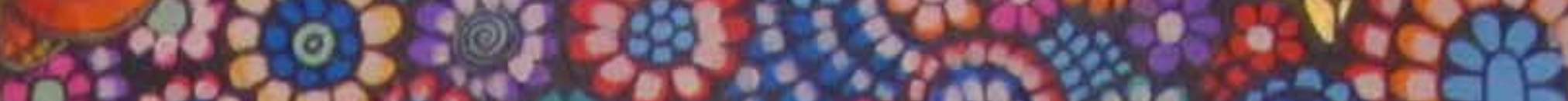

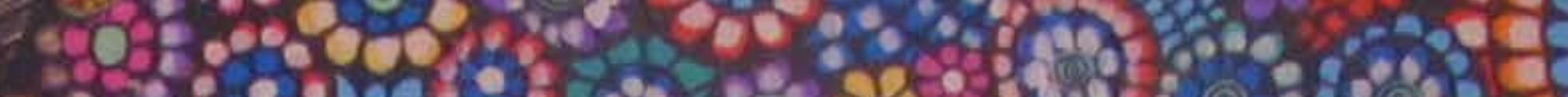

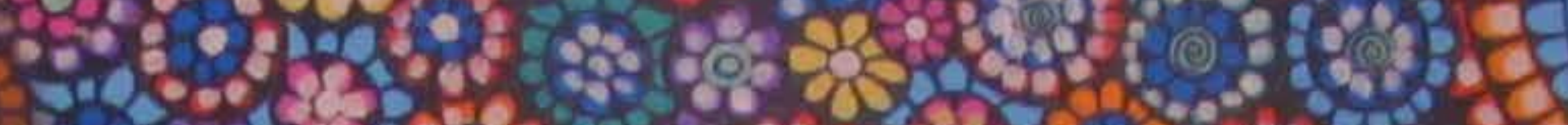

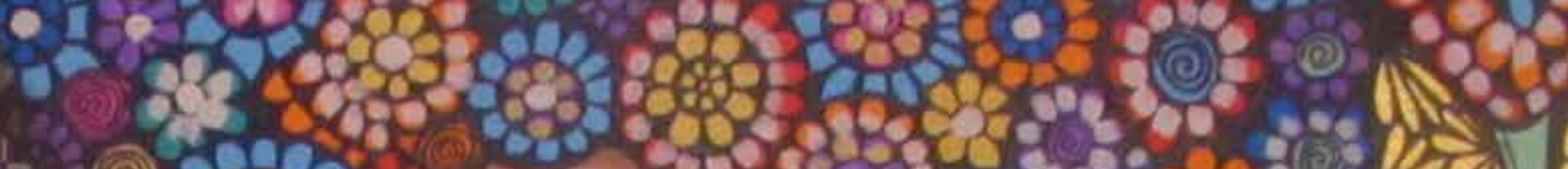
(10) (2) (1) of3 80800908.

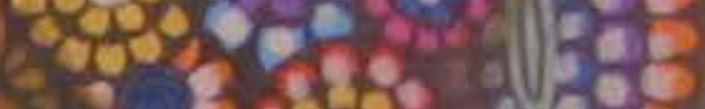

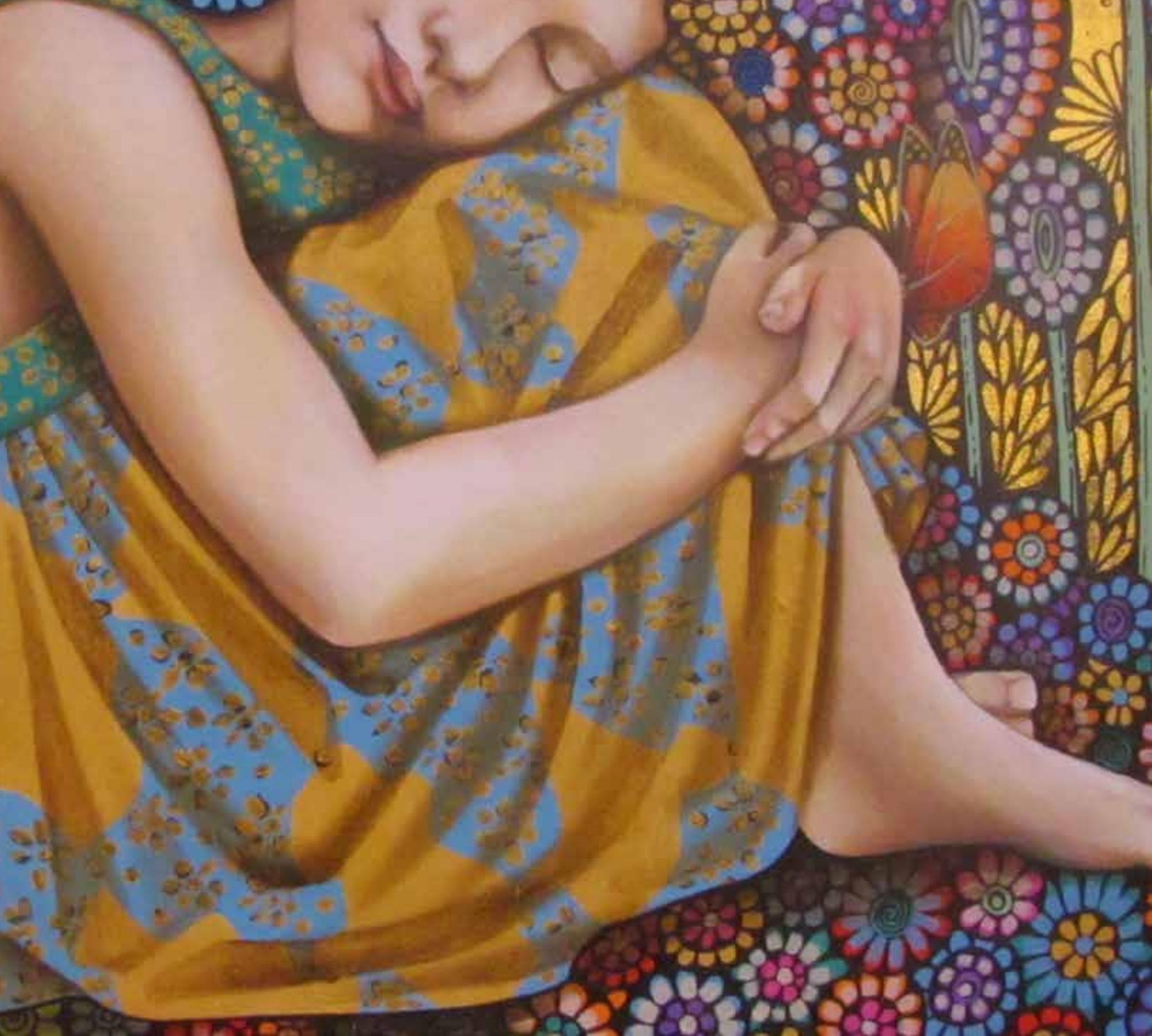

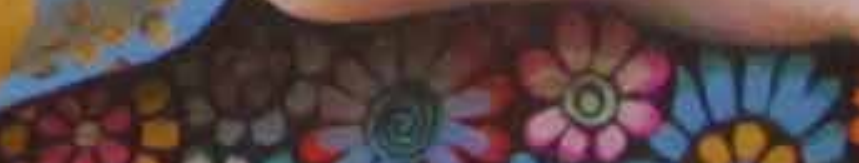

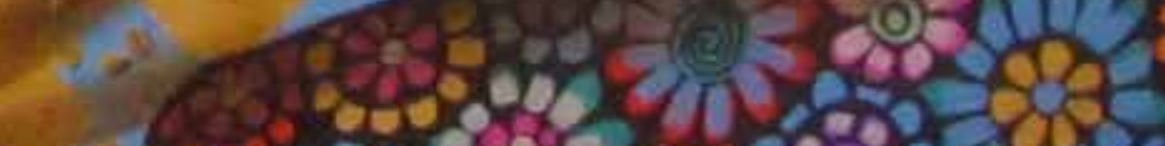




\section{TODO ESTA AQUÍ}

Donde se concentra la belleza del Caribe, donde hay playas que te llenan de ilusión, ríos caudalosos, bosque tropical hermoso y un paisaje que estremece el corazón....

\section{CORO}

Todo está Aquí, la magia del Caribe azul, el sol, la playa, Honduras es el mar, es la verde montaña, la gente amable que hará tu estadía feliz, TODO ESTA AQUÍ somos orgullo catracho, tambor, cultura, somos trabajo, corazón, café de altura aquí esta Honduras solo tenes que venir.

TODO ESTA AQUIIII...

Cheque para decir todo bien, un vaya pues, una sonrisa hoy te invitan a venir, somos tierra de oportunidades, hay culturas milenaria... Hay tanto por descubrir.

Guillermo Anderson 


\title{
3. Modelos económicos: su influencia en la geografía del desarrollo hondureño
}

\author{
Oscar Oswaldo Meza Palma ${ }^{1}$ \\ DOI: https://doi.org/10.5377/pdac.v16i0.10227 \\ Recibido: 31/01/2020 - Aceptado: 27/03/2020
}

\begin{abstract}
Resumen: Este artículo incursiona en el problema de polarización socioeconómica de la sociedad hondureña, cuya fuerza productiva y modernidad se han concentrado en apenas un par de polos urbanísticos e industriales de desarrollo², a expensas del resto mayoritario de regiones internas, donde se padecen altos grados de desigualdad y postergación. Se propone una explicación de sus causas y consecuencias, desde una perspectiva histórica que revisa un período a partir de 1899 hasta la fecha, reflexionando sobre las implicaciones que tuvieron las decisiones de política y los modelos de desarrollo económico adoptados por la clase gobernante en el devenir del tiempo para encausar un desarrollo equitativo. El estudio revela la influencia que esta combinación de aspectos inherentes a la toma de decisiones de más alto nivel jugó un rol determinante para moldear nuestro actual mapa de asimetrías entre regiones internas de país; que hoy día debilita esfuerzos hacia un despegue económico inclusivo de nuestra sociedad. Se sustenta una información de valiosa importancia en la planificación del desarrollo frente a los ingentes desafíos de la globalización en la que estamos inmersos.
\end{abstract}

Palabras clave: modelos económicos, desarrollo regional, globalización neoliberal, desigualdad, historia de Honduras.

\section{Economic models: their influence on the geography of Honduran development}

\begin{abstract}
This article delves into the problem of socioeconomic polarization of Honduran society, whose productive force and modernity has been concentrated in just a couple of urban and industrial development poles, at the expense of the majority of internal regions, where high levels of inequality and postponement are suffered. An explanation of its causes and consequences is proposed from a historical perspective that reviews a period from 1899 to date, which allows us to reflect on the implications of the political decisions and economic development models adopted by the ruling class in the future of time, to efficiently lead to equitable development. The study reveals the influence that this combination of aspects is inherent in the decision making of the highest level plays a decisive role in shaping our current map of asymmetries between country regions, which today weakens efforts towards an inclusive economic takeoff of our society. Information of valuable importance is sustained in development planning in the face of the enormous challenges of globalization in which we are immersed.
\end{abstract}

Keywords: economic models, regional development, neoliberal globalization, inequality, history of Honduras.

\section{Introducción}

La extrema desigualdad e inequidad en la estructura social hondureña es quizá uno de los problemas que mejor expresa el fracaso de las políticas de desarrollo implementadas a lo largo de su historia. Sus distintas manifestaciones pueden fácilmente captarse entre élites que concentran elevados niveles de riqueza y segmentos poblacionales que padecen de hambre crónica; entre los que acceden a una educación de calidad y tecnologías que facilitan su inserción al mundo laboral, en contraste de aquellas personas y regiones marginadas que carecen incluso de lo elemental como el agua potable.

Esta situación conlleva grandes barreras en la lucha por erradicar la pobreza actual y emerger como na- ción de manera más competitiva, ya que fracciona y debilita la sociedad entera dado que limita la plena incorporación de importantes regiones geográficas y sus poblaciones a las actividades productivas generadoras de crecimiento económico (Stiglitz, 2012, pp. 1-6); (Milanović, 2011, pp. 2-6). Paralelamente nos pone en desventaja frente a otras naciones que compiten por integrarse con éxito a la modernidad del presente siglo. Esto último se perfila como una gran amenaza en nuestros contextos de pobreza, debido a los altos requerimientos de capital humano, innovación y productividad que el actual orden económico globalizado demanda para permanecer en los linderos de tolerancia, o de lo contrario ser arrastrado a periferias infrahumanas de donde es cada vez más difícil salir.

1 Profesor Titular IV de la UNAH, en el Centro Regional Universitario de la Región Central. Ingeniero Agrónomo con estudios de Maestría en Tecnología de Riego y en Proyectos de Desarrollo. Actualmente cursando un programa doctoral en la Universidad Politécnica de Madrid, UPM, España. e-mail: oscar.meza@unah.edu.hn

2 Ambos polos de desarrollo conocidos como Región Metropolitana del Valle de Sula y la región Metropolitana del Distrito Central principal centro político y financiero del país. 
Este trabajo suma a las preocupaciones que procuran explicar la desigualdad espacial: aquella que en el tiempo se ha formado entre las distintas regiones internas del país, en las que claramente se observa una polarización entre una minoría de regiones metropolitanas de mayor densidad poblacional llamadas polos de desarrollo, por sus dinámicas productivas industriales y servicios urbanos y una mayoría de regiones intermedias y rurales en las que se exteriorizan sendas desigualdades y limitaciones para su crecimiento económico con escasa oportunidad y capacidad de sus poblaciones para superar condiciones de vulnerabilidad social. Una atrofia en la estructura socioeconómica de país, debida principalmente a largos períodos de crecimiento desigual (Modrego \& Berdegue, 2016, pp. 17-23); (Tellez, 2011, pp. 87102) que mantiene en letargo las economías de esas regiones rezagadas, además que por su vecindad y efectos recurrentes como la migración e inseguridad, tiende a frenar o restringir el potencial de crecimiento de las regiones más dinámicas (Fortich, 2010, pp. 10-13); (Kay, 2009, pp. 5-9); (Gutiérrez Casas, 2007) (Aguilar, 2016, pp. 87-90).

Al respecto, la ciencia del desarrollo tiende a coincidir que las asimetrías socioeconómicas entre territorios no se forman de manera espontánea, sino como resultado de la acción humana en su interrelación con el entorno natural, pero al pasar a sociedades organizadas el uso de los recursos y creación de valor de intercambio se explica mejor desde procesos de decisión de políticas públicas, para lo cual los gobiernos nacionales tienden a adoptar modelos de desarrollo económico que han visto funcionar en otros lugares quizá adaptándolos medianamente a realidades específicas (Modrego \& Berdegue, 2016, pp. 17-20); (Ochoa, 2015, pp. 3-9). De ello es razonable pensar que son las políticas y modelos de desarrollo experimentados en cada país, donde subyacen los elementos de análisis que mejor pueden explicar causales de estas disparidades o convergencias en el caso de países que lo han logrado. Esta lógica también se sustenta por la evidencia en varios países que alcanzaron la prosperidad, incluso bajo condiciones de escasez de recursos naturales.

Sentadas estas premisas, se propone estudiar ¿Cómo la política y los modelos económicos experimentados en distintos gobiernos a lo largo del tiempo, se conjugaron para conformar ese mosaico de brechas en el territorio nacional? Desde esta perspectiva se observa una secuencia de eventos desde las concesiones mineras y bananeras de fina- les del Siglo XIX hasta la integración al CAFTA del presente Siglo XXI, que en mayor o menor medida han moldeado con duro cincel su actual y caprichosa "versión de desarrollo hondureño", sus patrones y mecanismos de actuación.

Bajo esta lectura se espera brindar una mejor comprensión de cómo ocurrió el surgimiento los dos polos que deciden el desarrollo nacional, donde se concentra más del $70 \%$ de la riqueza financiera del país, y hacia donde se destina el $85 \%$ del presupuesto nacional ${ }^{3}$ en contraste y reforzando brechas con una amplia geografía de regiones desfavorecidas y postergadas, dispersas a lo largo y ancho del territorio nacional entre las que se destacan 9 territorios de pueblos indígenas y afrodescendientes entre los 236 municipios con baja clasificación de desarrollo (DGL.Hn, 2015, pp. 16-32).

Se puede entender como las decisiones coyunturales se inclinaron a la costa norte; luego se concentraron en la región del Valle de Sula, llevada por eventos históricos hasta convertirse gradualmente en una metrópoli industrial, con gran potencial para generación de riqueza, igual que las ciudades del municipio del Distrito Central (Tegucigalpa y Comayagüela) constituidas como el principal centro político y mercado de servicios asociados a la modernidad. Ambos polos influenciando a su vez una serie de intercambios económicos, migratorios, culturales con el resto de regiones vecinas; tejiendo así una dinámica de importante valor en la planificación del desarrollo nacional; cuya comprensión puede tomarse en cuenta como una condición ineludible para el diseño de nuevas estrategias en correspondencia con desafíos del momento.

El artículo presenta los principales vértices históricos que marcan el curso del desarrollo, resaltando en esa trayectoria el papel que paralelamente juegan las teorías del desarrollo que dieron paso a paradigmas hemisféricos que influenciaron los gobiernos nacionales en cada época; mediante lo cual se puede comprender mejor el mapa de desarrollo actual en su tejido socioeconómico, político y cultural.

\section{Metodología}

El problema de la desigualdad socioeconómica, ha sido una preocupación abordada por varios autores, sobre todo enfocada en explicar esa creciente polarización entre regiones ricas y muy retrasadas que caracterizan la geografía nacional (Ochoa, 2015); (Falck, 2000, pp. 3-9), tales estudios tienden a sus-

3 Según FOSDEH informe dic. 2017, datos de Banco Central de Honduras 2018, proyecciones de población INE/SEN. 
tentar hipótesis de esas asimetrías en cuestiones relacionadas a la configuración territorial de vertientes hídricas, topografía irregular y sus derivas agroecológicas que determinan unas regiones más productivas que otras, lo cual es asociado al crecimiento económico. También una agricultura de subsistencia de corte indígena y extendida culturalmente en varias regiones montañosas pudieron haber favorecido su exclusión del tren de desarrollo intenso y moderno que hoy se concentra apenas en una franja territorial, que según descripción de M. Falck, tiene la forma de una T: un corredor que conecta ambas costas, zonas metropolitanas y principales ciudades hondureñas (Falck, 2006, pp. 02-12); (Molina, 1984, pp. 38-42).

Entretanto el presente análisis argumenta que las mayores razones que explican tales asimetrías provienen de las decisiones en materia de política de desarrollo, influenciadas por la adopción de modelos económicos foráneos cuya combinación entreteje un mal desarrollo que, a lo largo del tiempo, ha definido nuestra geografía económica.

Para sustentar esta hipótesis, se recurre a información documentada de probada fidelidad histórica nacional. Se ha logrado colocar en el eje del tiempo, principales eventos de decisión política observados en la sucesión de gobiernos: el rumbo y discurso de prosperidad que marcaron sus decisiones, contrastando el rol que los modelos económicos paradigmáticos jugaron en cada momento de esa trayectoria de desarrollo. Se revisa un período largo que viene del gobierno de Terencio Sierra (1899) hasta la fecha y se presenta un mapa donde se compara la distribución espacial de municipios más ricos y pobres, a partir de la más reciente categorización municipal de la Secretaría de Gobernación en la Dirección de Gobiernos Locales (Informe 2015).

\section{Discusión de resultados}

\subsection{Modelos de desarrollo y la política económi- ca en la perspectiva histórico}

\subsubsection{Modelo de Enclave Bananero}

La historia del desarrollo hondureño, a partir de la independencia y advenimiento de una nueva hege- monía capitalista a mediados del Siglo XIX evidencia una marcada relación de dependencia con los centros de poder, una cuestión que como se verá más adelante jugará un papel determinante en el diseño de las políticas y adopción de modelos económicos que en conjunto configuran la experiencia de nuestro desarrollo.

Las primeras ideas de desarrollo tenían una influencia extractivista, en el sentido que toda la geografía nacional era vista como un tesoro de recursos mineros, maderas preciosas y especies vegetales y animales exóticos de gran valor comercial en el mercado post colonial, cuya actividad generaba incalculable riqueza únicamente para la élite que heredó privilegios del régimen monárquico, más ninguna para las regiones explotadas.

Luego casi inmediatamente después del período reformista de Marco A. Soto ${ }^{4}$, empiezan los cimientos de lo que sería otra fase de colonización basada en el poder del capital y la subordinación de caudillismos locales que abren el camino hacia una economía de enclave, lo que seguidamente ya en los albores del Siglo XX desembocaría en lo que puede denominarse Modelo Económico Bananero ${ }^{5}$ : que emerge gracias a las concesiones de grandes extensiones de tierra, a beneficio de compañías norteamericanas dedicadas a la plantaciones masivas del cultivo del banano para la exportación y quienes imponen los territorios donde conviene expandir este cultivo por condiciones de fertilidad de suelos y facilidad de transporte marítimo hacia mercados internacionales (Laínez \& Meza, 1973, pp. 23-27); (Euraque, 1991, pp. 11-25).

Previo a este modelo de carácter agrícola exportador, el sistema productivo hondureño era eminentemente feudalista y estaba distribuido en varias regiones próximas a poblaciones coloniales ${ }^{6}$, la economía de entonces se sustentaba en agricultura de subsistencia campesina y extracción minera asalariada, hasta finales del Siglo XIX, momento que los gobiernos de la época encabezados por sus titulares: Terencio Sierra y luego Manuel Bonilla, abrazan este modelo económico de enclave como principal estrategia de desarrollo ${ }^{7}$, con lo que justificaban la función desarrolladora de sus gobiernos, enarbolando la bandera del progreso y oportunidades de empleo a una po-

4 Período del Presidente Marco A. Soto: 1876 - 1883.

5 Es un modelo "regional" porque su principal zona de acción fue la franja costera norte y "hacia afuera" porque se basaba en exportaciones de materias primas y el capital era eminentemente transnacional centrado en el banano, madera y minería. 6 Las principales poblaciones conformadas desde la colonia eran: Real Villa de San Miguel de Tegucigalpa de Heredia, las vías provinciales de Comayagua y Gracias Lempira.

7 Se remite la lectura de "Prisión Verde" de Ramón Amaya Amador, y ver reseñas históricas del siglo pasado.

Revista Población y Desarrollo: Argonatuas y Caminantes, vol.16, 2020 
blación postergada por el largo feudalismo colonial; las actividades productivas de gran escala se concentraron en la costa norte del país en especial la región costera que va desde Puerto Cortés, La Ceiba y parte del Valle del Aguán, dado que la élite gobernante armonizó sus prioridades de gobierno, con las transnacionales bananeras quienes por rentabilidad y logística prefirieron este territorio (Argueta, 1989, pp. 37-54).

La región costera concentró principalmente la actividad productiva y comercial y fue hacia donde emigró más del $70 \%$ de la fuerza laboral nacional, atraída por las oportunidades de empleo, quedando gradualmente despoblado el resto de territorios del interior (Murga, 1985; 2 edic., pp. 173-177); (Morris, 1977, pp. 29-35) incluido lugares que en el período colonial fueron política y económicamente importantes.

Habida cuenta del impresionante despliegue del proyecto bananero que, en su rápida expansión, descombró miles de hectáreas de llanuras y bosque tropical, construyó muelles, abrió caminos, líneas de ferrocarril, barracas, en fin, un tropel de acciones que significó, la mayor demanda laboral de la historia de Honduras para ese momento siguiendo esa fuerza gravitacional, también se encaminaron las políticas públicas nacionales cuyo foco de atención estaba inclinado a esa región costera, quedando opacadas las atenciones para el resto de territorios del interior, algunas incluso relegadas al olvido gubernamental, a expensas con una agricultura rudimentaria de autoconsumo; de lo cual se deduce que el impacto en promover el desarrollo nacional estuvo principalmente localizado a la franja costera norte, significando un mayor desequilibrio en la geografía económica, debido a que este modelo de enclave no tenía vínculos con el resto de la actividades comerciales del país (Molina Chocano G. , 1976, pp. 17-28).

\subsubsection{Modelo Primario Exportador}

A partir de los 50 se advierte un giro en el curso del desarrollo regional hondureño explicado por una doble coyuntura: ya que en el plano hemisférico de la geopolítica internacional, se estaban propiciando decisiones supranacionales buscando inmunizar conflictividad en la política de Latinoamérica, una región sumamente estratégica debido al clima de conflictos ideológicos comunista-capitalista desata- do por bloques de poder (período de guerra fría) que amenazaba expandirse a diferentes países socialmente inconformes y por lo cual era necesario impulsar y acompañar su desarrollo económico y estabilidad política, repotenciando el aparato productivo y por tanto su despegue económico (Jimenez, Dic. 2002, pp. 7-12); (Montobbio, 1997, p. 31); (Molina Chocano G. , 1981, pp. 11-15). Tal estrategia se inspiraba y legitimaba desde el ejemplo de la vertiginosa recuperación económica observada en la Europa Occidental de postguerra, que fue lograda gracias a la modernización de su aparato productivo industrial y agrícola, lo cual podría ser extrapolado a naciones rezagadas de nuestro hemisferio ya que el rudimentario sector agropecuario fue visto como uno de los obstáculos "estructurales" al desarrollo de las economías latinoamericanas (Barquero, 2007, pp. 0816) (Artal, 1999, pp. 2-10).

En el plano nacional lo anterior hace paralelo con la inestabilidad política y social del Estado hondureño, motivado en parte, por el evidente declive del modelo bananero debido a su insuficiente capacidad como motor de prosperidad. La huelga bananera del año 54 revelaría ese descontento social (Euraque, 1991, pp. 11-25); (Laínez \& Meza, 1973, pp. 22-30) y sus consecuencias en alguna medida trajeron cambios en las prioridades políticas que obligaron al Estado reformar su constitución ${ }^{8}$ y en sus mandatos: buscar compensar deudas de bienestar social, desempleo creciente en una economía estancada en muchos aspectos debido a que las ganancias del monopolio bananero de más de siete (7) décadas, en lugar de derramarse a la sociedad al menos la costera, fluyeron principalmente hacia las transnacionales y élites asociadas, quienes en cierta medida, acostumbraban "arreglar" exoneraciones fiscales que apenas dejaban lo mínimo al tesoro nacional (Bueso, 1987) (Criterio.hn, 2018, pp. 1-4).

Era preciso fortalecer el sector agrícola para que pudiera producir alimentos suficientes, además de contribuir a las exportaciones y generar insumos para la producción industrial. De esta convergencia de coyunturas históricas, es que podría explicarse la influencia que el paradigma de modernización como un nuevo modelo económico distinto al enclave, provocó en la política de desarrollo nacional, alentando a la élite gobernante para irse sacudiendo del modelo bananero y girar hacia aquellas vías de desarrollo promovidas por los organismos internacionales ${ }^{9}$ como respuesta

8 Se refiere a la Constitución de 1957 en el gobierno de Villeda Morales.

9 La OCDE: Organización para la Cooperación y el Desarrollo Económico lideraba un conjunto de instituciones técnicas y financieras. 
a problemas socioeconómicos derivados del largo descuido al sistema productivo interno, que para el momento dependía lógicamente de la producción bananera y de una agricultura semi feudal en el resto del país.

Este paradigma de desarrollo comportaba una serie de postulados teóricos sustentados en la creencia que para lograr el desarrollo desde la visión eurocéntrica, debían cumplirse una serie de etapas planteadas por Rostow, para asegurar una ruta de crecimiento económico, que mediante ese modelo de organización socioeconómica lograron un nivel industrializado (Rostow, 1963, p. 26), de tal modo que los países rezagados que asumieran tales etapas podrían emprender ese camino directo a la prosperidad, con solo repetir el ejemplo de las economías avanzadas.

Bajo ese esquema, el desarrollo dependía de saltos tecnológicos definidos como condiciones necesarias para alcanzar altos niveles de productividad en sectores como la industria, la construcción y la agricultura, este último rubro importante de la economía por su papel estratégico en la seguridad alimentaria, su grado de tecnificación se tradujo en muchos países, como el paradigma de "la revolución verde" que a diferencia de otras revoluciones ideológicas, esta sí podría erradicar el hambre y la pobreza. Una modernización que se lograba con la adopción de una serie de prácticas y tecnologías, entre las que se incluyen mejoramiento genético de variedades vegetales y razas de ganado, mecanización de tierras con empleo de sistemas de irrigación, así como el uso de fertilizantes y plaguicidas. Todo un paquete tecnológico que posibilitaba alcanzar altos rendimientos productivos.

De estas convicciones científicas, la revolución verde se convirtió en el discurso de moda en élites políticas, empresariales y académicas en el continente, lo que alentó que Honduras también se sumara a este gran proceso de adopción, que en medio de sus problemas políticos y económicos, significaba para la clase gobernante una tabla de salvación con suficiente potencial para superar la dependencia transnacional de la economía del banano y minería.

Contando con la ayuda de organismos financieros y coyunturas como programa Alianza para el Progreso promovida por el gobierno de Kennedy ${ }^{10}$, se desplegaron programas de ampliación de la frontera agrícola y diversificación productiva acompañados de crédito agrícola y asistencia técnica a fin de impulsar la economía mediante exportaciones, generación de divisas y activar el mercado nacional, para lo cual se ocupaba incorporar a otras regiones del país a la producción agropecuaria como estrategia de desarrollo regionalizado.

Los planificadores del desarrollo de la década de los 60 , visualizaron la ampliación de la frontera agrícola, esta vez más allá de la costa norte bananera, abriendo paso a una política regional más articulada de desarrollo, basada en el potencial productivo y según las condiciones agrológicas de cada región para asegurar mayor productividad (Molina Chocano G. , 1976, pp. 18-23); (INFOAGRO, 2009) bajo esos criterios si bien se continuó privilegiando la costa norte hondureña como el Valle de Sula y el Valle de Lean, se incluyeron nuevas regiones que fueron beneficiadas con cierto capital fijo productivo como al Valle de Comayagua que se le dotó del primer sistema de riego por gravedad y de un Centro Nacional de Ganadería equipado para la reproducción de razas de ganado importado y transferencia tecnológica, otras inversiones agroindustriales para producción de azúcar y empacadoras de carne se registran en el Valle de Sula, Cantarranas y Choluteca, mientras en el Valle de Quimistán se registran mejoras tecnológicas para procesamiento de tabaco; en los Valles de Olancho y del Aguán se impulsaron como productores de granos básicos. Como resultado de estas inversiones y de transferencias de tecnologías más los altos precios internacionales de exportación, rubros como: la carne, el algodón y el café se convirtieron por primera vez en importantes productos de exportación, alcanzándose valores por el orden de 22 millones de Lempiras (Euraque, 1997, pp. 11-14). En cuanto a producción de granos básicos se alcanzó la autosuficiencia incluso con exportaciones a países vecinos ${ }^{11}$ en menor cuantía también se logran exportaciones de azúcar, madera y tabaco.

No obstante de tales resultados, se piensa que en la versión hondureña a diferencia de la experiencia suramericana, la revolución verde fue débil y de resultados insuficientes para propiciar una economía agraria exportadora sostenida y rentable, lo cual puede verse en los indicadores macroeconómicos como el PIB que en ese período de 10 años solo incrementó de 37.0 a 62.2 millones de dólares, mientras la pobreza se acercó a inicios de los 70 a un $34 \%$ (BCH, 2018) (Morris, 1977). La principal razón de esta circunstancia fue la baja intensidad de in-

10 De la Alianza para el Progreso surgió la STICA como Agencia Técnica de Cooperación Agrícola.

11 Varios artículos periodísticos denominaban la producción hondureña de maíz, sorgo y frijoles como el granero de C.A. 
versiones público privadas debido sobre todo a las paupérrimas economías e ineficientes estructuras locales en las regiones del interior donde se abrieron proyectos agropecuarios.

\subsubsection{Modelo de Industrialización por Sustitución de Importaciones (ISI)}

La falta de resultados de la experiencia anterior más los problemas económicos internos alentados por un período de recesión económica en países del norte industrializado a inicios de los 70 (Jimenez, 2001, pp. 9-13) (Jimenez, Dic. 2002, pp. 9-13), más la caída internacional de precios de materias primas agrícolas, fueron los factores que fertilizan y justifican en la discursiva del gobierno de López Arellano para negociar los préstamos y la asistencia necesaria para articular un modelo de desarrollo económico diferente, basado en la industrialización de la economía de país, cuya fuerza productiva y exportadora crearía todos los empleos y circulación monetaria entre hondureños como para dinamizar el mercado interno a lo largo y ancho del país. Pero esta vez no se cometerían los errores de improvisación pasados, ya que la casa de gobierno presumía de un inédito plan de nación, que para ese entonces ya era promocionado en círculos políticos y empresariales como genial respuesta (Euraque, 1997, pp. 17-56); (Molina Chocano G. , 1981, pp. 11-15) (Ochoa, 2015, pp. 7-22).

Por tanto es la década de los 70 que le corresponde ver su influencia en el desarrollo hondureño, pues suponía proyectos más agresivos de los probados hasta ese momento, que generaran mayor valor agregado por medio de las transformaciones industriales, a sabiendas que solo con la débil economía agraria existente en el país no se podría emerger del subdesarrollo que se padecía y ubicarse a la par de países incluso vecinos como Costa Rica y Panamá, que para ese momento ya ostentaban crecimientos sostenidos en sus economías.

Esta sería la alfombra discursiva que legitimó la negociación de deuda externa ante organismos financieros para impulsar la industria robusta y de alta escala al amparo también de las influencias cepalinas por ese entonces un órgano supranacional con especialidad en el desarrollo económico de países latinoamericanos (Kay, 2009, pp. 5-9) quienes con su contingente de renombrados economistas promocionan el modelo ISI de Industrialización para Sustitución de Importaciones y para convencer sectores empresariales y académicos, traen como carta de presentación las experiencias exitosas de corporaciones que impulsan las inversiones industriales como el FORPO de Chile y la Casa Financiera de México, y Costa Rica presentados como referentes de lo que también se podía hacer en Honduras. De este modo, se crean los consensos con la empresa privada contando con el auspicio del gobierno promotor para dar nacimiento al experimento hondureño con su propia corporación financiera que pasaría a denominarse CONADI ${ }^{12}$ con un carácter público privado dado el origen mixto de su capital, una institución creada para impulsar este modelo económico vanguardista (Molina Chocano G. , 1981, pp. 11-15); (Murga, 1985; 2 edic., pp. 167-171). Fue tal la importancia de CONADI que en los seis años entre 1974 y 1980, fue responsable por medio de sus empresas del $74 \%$ de toda la inversión nacional, de igual manera se crearon otras corporaciones empresariales en rubros más específicos como la industrialización de madera, negocio del Banano CORFINO $^{13}$, COHBANA ${ }^{14}$ y grandes empresas estatales como la COHDEFOR $^{15}$, HONDUTEL ${ }^{16}$, IHMA $^{17}$ entre otros.

Este modelo económico a ensayarse en Honduras presumía un andamiaje conceptual superador del problema económico latinoamericano que en suma conforma el cuerpo teórico del paradigma de la dependencia (Fortich, 2010); (Puente, 2003, pp. 1120); (Morris, 1977, pp. 32-41), una teoría articulada por intelectuales de la $\mathrm{CEPAL}^{18}$, cuyo enfoque afirma que desarrollo y subdesarrollo son procesos históricamente simultáneos, resultado de la expansión del capitalismo a nivel mundial, deja saldos negativos a las economías de exportación primaria debido a desequilibrios en los intercambios comerciales con países compradores industrializados lo que se evidencia en la división internacional del trabajo entre países productores de materias primas y países productores de bienes manufacturados. De manera que el modelo exportador de materias primas, comporta mecanismos empobrecedores de los países agroexportadores.

12 CONADI: Corporación Nacional de Inversiones.

13 CORFINO: Corporación Forestal Industrial de Olancho.

14 COHBANA: Corporación Hondureña del Banano.

15 COHDEFOR: Corporación Hondureña de Desarrollo Forestal.

16 HONDUTEL: Empresa Hondureña de Telecomunicaciones.

17 IHMA: Instituto Hondureño de Mercadeo Agrícola.

18 CEPAL: Comisión Económica para América Latina y el Caribe. 
El supuesto central de este modelo (se caracteriza por ser hacia adentro) es que la creciente dependencia de importaciones y tecnologías postraba las economías nacionales generando altas tasas inflacionarias situación que arrastraba a la pobreza a la mayoría de la población, limitando su capacidad de consumo y por ende mercados deprimidos. Así se postulaba que el progreso estaba estancado si los países latinoamericanos no lograban romper este círculo vicioso del subdesarrollo. Por ello el modelo ISI poseía la doble solución que mientras se construye la capacidad industrial de productos de consumo masivo y exportable, se crean los empleos suficientes para impulsar niveles de consumo; recreándose un círculo virtuoso hacia la prosperidad.

Amparado en esas halagadoras promesas, se despliegan acciones que tienden a identificar a lo largo y ancho del territorio nacional, las plataformas agrícolas forestales y mineras que sustentaran la articulación de una industria diversificada. Bajo esa estrategia fue notable la primera división del país por regiones productivas especializadas así tenemos una región de litoral ganadera y bananera, amplias plantaciones cítricas y de palma africana para los valles de Lean y Aguán donde se construyeron centros de acopio y procesamiento para lácteos y aceite vegetal, las regiones densamente forestales de Olancho, Trujillo, La Paz e Intibucá se incluyeron en los planes de CORFINO, otras regiones montañosas de Copán, Santa Bárbara se financian proyectos para beneficiado y exportación del café. En el Valle de Comayagua y alrededores se prioriza para la agroindustria hortícola mientras en otros valles de la zona centro sur se ubican o amplían plantaciones de caña de azúcar, algodón, entran en operación ingenios de Yojoa, Cantarranas y Choluteca. La región del Valle de Sula incluido su modernizado Puerto Cortés, para ese momento ya posee condiciones competitivas atractivas para merecer inversiones nacionales y externas que explica la concentración de la mayor cantidad de industrias y empresas exportadoras de gran tamaño, solo en el caso de la CONADI se llegó a tutelar 68 empresas del sector industrial empresarial (Morris, 1977), (FOSDE, 2017, pp. 2-11).

Sin embargo y a pesar del gran despliegue arriba explicado, que significó el mayor contingente de proyectos de inversión y creación de empresas industriales en la historia económica hondureña, su continuidad y sostenibilidad se vio comprometida por los informes de insolvencia económica de los principales órganos financieros como la CONADI, CORFINO y COHBANA instituciones vertebradoras del Modelo ISI quienes en su momento se les confiaron inmensos volúmenes de capital fresco provenientes en buena parte de empréstitos externos y que en menos de 10 años después de ponerse en marcha cayeron en banca rota y obligaron a un triste período de liquidaciones sucesivas. Dejando al país ya en la década de los 80 , sumido en una crisis económica con pérdidas que significaron el $25 \%$ de toda la deuda externa nacional, según la Comisión Episcopal de Honduras (CESPAD, 2016); (Criterio.hn, 2018).

Varios estudios coinciden sobre las razones que llevaron al fracaso financiero de estas corporaciones hondureñas que no pudieran sostenerse como en las versiones chilenas, mexicanas y de Costa Rica. Los desórdenes de los gobiernos militares aliados con élites político-económicas de finales de los 70 más los ruidos de una transición democrática hacia gobiernos civiles de principios de los 80 fueron combinaciones de poder malignas para fomentar una especie de anarquía y corrupción en todas las instituciones del Estado. Esto resultó en la quiebra prematura de principales empresas estatales e instituciones corporativas, que se suponía impulsarían un desarrollo sostenido y de largo plazo; además la protección estatal de las inversiones industriales, condujo a severas distorsiones en los precios internos y a la constitución de una burguesía incapaz de competir en el mercado internacional.

Mientras crecía la inminente crisis inflacionaria y monetaria, la clase gobernante de los 80 , en lugar de judicializar las fraudulentas operaciones de aquellas empresas e instituciones de inversión, denunciadas; "construyeron" un discurso neoliberal que atribuía a fallas estructurales del modelo económico intervencionista, esos malos resultados de la empresa estatal. De este modo se justificaron cierres forzados de la gran mayoría de estas corporaciones.

Se suma a ese mal, la mediática manipulación de la sociedad, en favor de la privatización de las restantes empresas que aún estuvieran de pie. Como "alternativa superadora" promocionaban su traslado al sector privado, donde debían funcionar mejor habida cuenta de una serie de incentivos fiscales concedidos (CESPAD, 2016, p. 4); (Criterio. hn, 2018, pp. 2-4); (Euraque, 1997) (Ochoa, 2015, pp. 4-16).

Revista Población y Desarrollo: Argonatuas y Caminantes, vol.16, 2020 


\subsubsection{El Modelo Económico Neoliberal}

Sin haber digerido los estragos financieros del modelo ISI y bajo una atmósfera de confusión política y de complicidades mediáticas y judiciales, estábamos los hondureños asistiendo a la inauguración del nuevo modelo económico neoliberal, que se fue expandiendo a inicios de los 90 por la audacia tecnócrata del gobierno del presidente Callejas y su polémica ley de reestructuración económica y ordenamiento fiscal del Estado hondureño.

Mediante subastas traspasaron decenas de empresas a manos privadas al tiempo que se clausuraron programas de asistencia técnica y crediticia que surgieron en el período de la reforma agraria, con lo que terminan de desaparecer estructuras de la revolución verde pasada.

El modelo económico neoliberal versión hondureña que surge en condiciones socioeconómicas ya precarias, sin duda hace eco de aquellas prescripciones de libre mercado, de privatizaciones y disminución del papel del Estado como planificador e interventor de las economías nacionales, establecida por el consenso de Washington ${ }^{19} \mathrm{y}$ alentado posteriormente por escuelas económicas neoclásicas predominantes como la llamada "Chicagos Boys". Recetas sustentadas en un cuerpo teórico que privilegia el mercado sin restricciones y la iniciativa empresarial como condiciones necesarias para impulsar el crecimiento económico a tasas sostenidas, bajo el supuesto que el mercado incentiva intercambios comerciales locales e internacionales desde procesos cada vez más eficientes y comporta mecanismos de redistribución de sus ganancias a las partes o países involucradas que se terminan derramando en la sociedad (Puente, 2003, pp. 3-5); (Jimenez, Dic. 2002, pp. 7-10). Por tanto, se confía al mercado la asignación de recursos para promover la competitividad y equidad social. El Estado se aparta de rectorar asuntos de la economía incluido aquellos mecanismos de planificación y regulación que ahora se consideran más bien un peligro, dado el anterior fracaso de la intervención estatal.

Sobre el impacto de este modelo económico en la política regional y sus procesos económicos se puede valorar en términos generales que fue negativo, ya que aquellas regiones del interior que cobraron importancia en los modelos económicos anteriores y donde emergieron proyectos ganaderos, hortícolas y agroindustriales, ya sin la ayuda gubernamental técnica y crediticia pasaron a estados de recesión o disminución de sus niveles productivos y de empleo, así se da cuenta de varios territorios en algún momento pujantes en producción de granos básicos, algodón, tabaco y ganadería, sus productores propietarios han desertado o se han sumado a la masa asalariada, incluso migrante (Meza, 2015, pp. 12-13), mientras las empresas transnacionales de agro exportación y agroindustria se están concentrando donde ya la infraestructura productiva es más competitiva; es decir un refuerzo que apunta hacia los polos de desarrollo y los fortalece.

Aunque las cifras del gobierno reflejan incrementos del PIB durante la década de los 90 que totalizan un $58.68 \%$ a lo largo de la siguiente década $(\mathrm{BCH}$, 2018), efectivamente, se pueden llegar a obtener resultados halagadores en términos macroeconómicos, pero esto no significa que la creación de riqueza o las capacidades productivas de crecimiento económico asociadas se hayan redistribuido equitativamente dentro de la economía nacional o que haya mejorado las condiciones de vida de la población.

Para varios autores, la siguiente etapa de la política neoliberal integracionista que se observa en la primera década del Siglo XXI, abrió puertas a una nueva ronda de globalización que se estaba demorando en posicionarse en nuestros contextos y se expande gracias al franqueo de los Tratados de Libre Comercio entre los Estados Unidos de América, Centro América y la República Dominicana (DRCAFTA ${ }^{20}$, y más recientemente Canadá, se espera mucha más inversión extranjera y mayor crecimiento económico. Pero otra vez las expectativas de desarrollo nacional colisionan con un modelo de actividad económica implacable pues mientras acá se privatiza y liberalizan los mercados, los países capitalistas desarrollados han recentrado su desarrollo en procesos de formación de bloques, que tienden a excluir a los países subdesarrollados de los principales flujos que dinamizan la globalización por lo que esta nueva promesa tiende a convertirse en mera utopía.

\subsection{La explicación del desequilibrio entre regiones}

Es notable que las políticas hondureñas de desarrollo históricamente se subordinaran a estrategias

19 Propuesto en el Gobierno de Reagan como medidas supremas para salir de la crisis económica de los 80.

20 El DR- CAFTA suscrito en Honduras en una primera fase en 1999 y una intensificación en el 2005 que comenzó aplicarse en el año 2016. 
y modelos económicos sin mayores adaptaciones a la realidad nacional. Lo cual es evidente desde el modelo bananero cuyo negocio exportador estuvo primeramente en manos hondureñas, quienes sistemáticamente fueron despojados desde las políticas de concesión (Argueta, 1989, pp. 42-49); (Molina, 1984, pp. 167-171), al tiempo que pasaron por alto diseñar en función de contextos diferenciados del paisaje nacional habitado por 9 pueblos indígenas y afro descendientes, una diversidad de regiones naturales y culturales distintivas. Como resultado hoy día son las regiones más pobres de Honduras a pesar de su riqueza en biodiversidad, conocimiento autóctono y demás expresiones culturales.

Obsérvese en el Cuadro $\mathrm{N}^{\circ} 1$ y Mapa $\mathrm{N}^{\circ} 1$, que en la región Valle de Sula recayeron todas las grandes iniciativas de desarrollo: desde el modelo bananero hasta las políticas integracionistas del CAFTA; iniciativas que trajeron dotaciones de infraestructura y de inversiones que explican su condición polar, mientras que la región metropolitana del Distrito Central: su condición política se aprovechó lógicamente para centralizar el sistema financiero y de servicios.

En el Mapa №1 elaborado a partir de la más reciente categorización municipal (DGL, 2015), se observa que los 19 municipios categoría "A" es decir, los más desarrollados se encuentran ubicados en las regiones que los modelos agrícolas exportadores y de industrialización privilegiaron más intensamente, mientras los restantes 111 municipios categoría "C" y 125 categoría "D" están ubicados fuera de esta área de influencia.

\section{Cuadro №1 Concentración geográfica de la economía hondureña influenciada por la convergencia histórica de política nacional y paradigmas de desarrollo económico}

\begin{tabular}{|c|c|c|c|c|}
\hline $\begin{array}{c}\text { Paradigma } \\
\text { teórico }\end{array}$ & $\begin{array}{l}\text { Teoría de la } \\
\text { colonización } \\
\text { capitalista }\end{array}$ & $\begin{array}{c}\text { Teoría de la } \\
\text { Modernización } \\
\text { La revolución } \\
\text { verde }\end{array}$ & $\begin{array}{l}\text { Teoría de la } \\
\text { dependencia }\end{array}$ & $\begin{array}{c}\text { Teoría } \\
\text { Neoliberal } \\
\text { Era de la } \\
\text { globalización }\end{array}$ \\
\hline $\begin{array}{c}\text { Modelos } \\
\text { Económicos }\end{array}$ & $\begin{array}{l}\text { Modelo de } \\
\text { Enclave } \\
\text { Bananero }\end{array}$ & $\begin{array}{l}\text { Modelo Primario } \\
\text { Exportador } \\
\text { Agrícola }\end{array}$ & $\begin{array}{c}\text { Modelo de } \\
\text { Industrialización } \\
\text { por Sustitución } \\
\text { de } \\
\text { Importaciones } \\
\text { ISI }\end{array}$ & $\begin{array}{c}\text { Modelo } \\
\text { Neoliberal o de } \\
\text { Liberalización } \\
\text { Económica }\end{array}$ \\
\hline Fase Intensa & $1912-1949$ & $1962-1969$ & $1972-1982$ & 1990 - actual. \\
\hline $\begin{array}{l}\text { Regiones de } \\
\text { mayor } \\
\text { concentración } \\
\text { económica }\end{array}$ & $\begin{array}{l}\text { Costa Norte, } \\
\text { Valle del } \\
\text { Aguán }\end{array}$ & $\begin{array}{c}\text { Costa Norte, } \\
\text { Corredor Central } \\
\text { y Sur }\end{array}$ & $\begin{array}{c}\text { Región Valle de } \\
\text { Sula, Región } \\
\text { del Distrito } \\
\text { Central y otras } \\
\text { regiones } \\
\text { dispersas. }\end{array}$ & $\begin{array}{c}\text { Se concentra } \\
\text { en regiones de } \\
\text { mayor ventaja } \\
\text { comparativa } \\
\text { preexistentes. }\end{array}$ \\
\hline
\end{tabular}

Fuente: elaboración propia a partir de la revisión documental (2019). 
Mapa N¹ Actual geografía económica. La disparidad socioeconómica interna

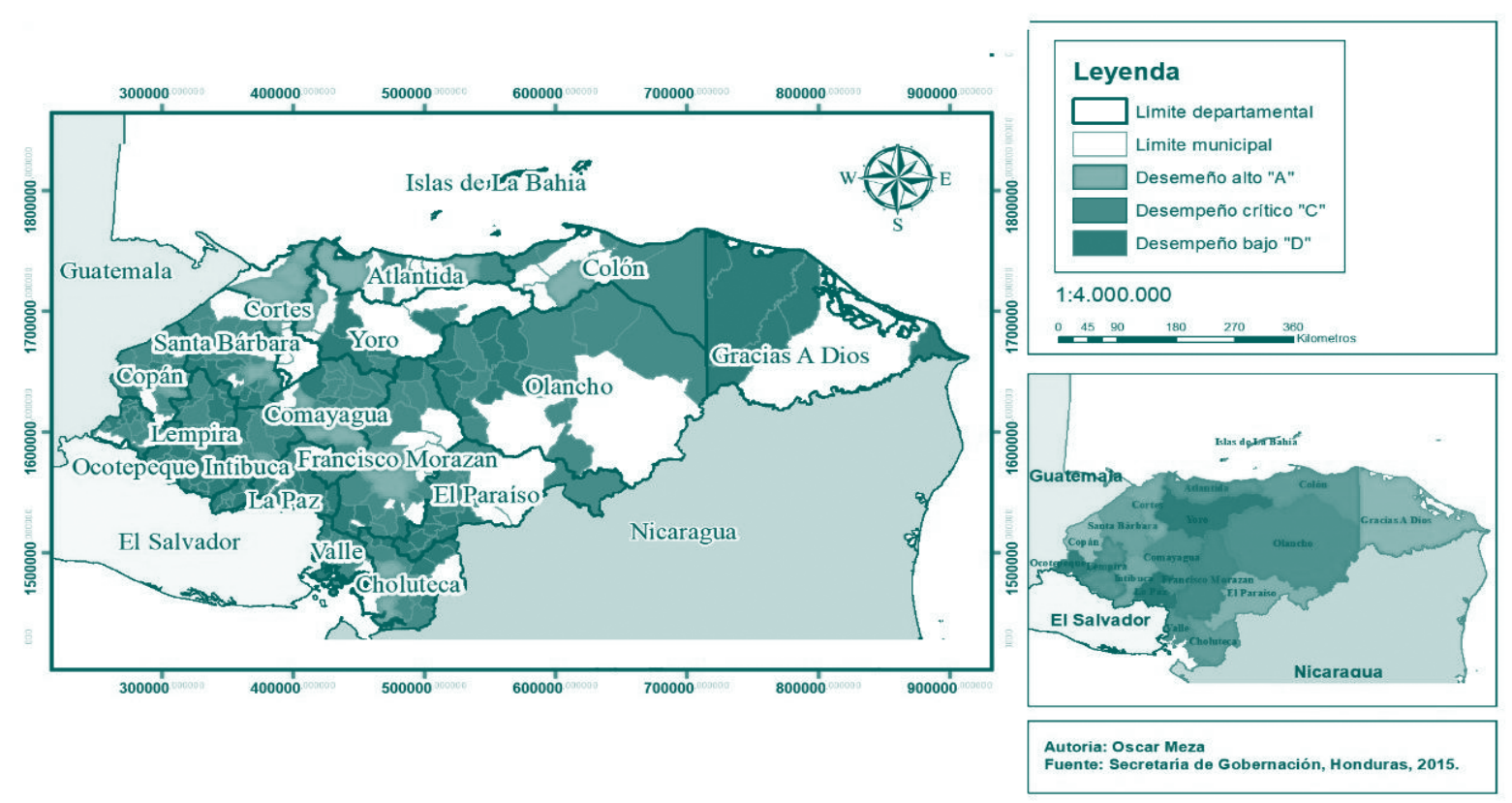

Fuente: elaboración propia con base en la categorización municipal (DGL.Hn, 2015).

Las regiones indígenas y rurales montañosas alejadas de centros urbanos son las que menos atención merecieron de la política incluso los datos de intervención a través de proyectos de desarrollo rural son recientes (IICA, 2008) y determinados desde la planificación central con escasa construcción de capacidades locales, lo cual se evidencia también porque esas regiones poseen los municipios más pobres del país.

La experiencia integracionista hondureña con países económicamente avanzados por medio de tratados como el CAFTA, abre paso a nuevos flujos de la globalización como una fase más compleja de la escalada neoliberal, cuya expansión en el territorio nacional, sus efectos e impactos aún son poco conocidos.

\section{Conclusiones}

Sobre la implicación de los modelos económicos y su influencia para determinar la geografía actual de prosperidad de país, puede afirmarse en el caso de los modelos de base agrícola, en tanto su lógica economicista centrada en ventajas comparativas que demandan bajos costos en los factores de producción, estas ventajas solo enriquecieron y consolidaron el capital transnacional, algo que fue consenti- do desde la decisión política caudillista, subordinado en avalar prioritariamente regiones costeras fértiles y planicies, cercanas a puertos y con disponibilidad suficiente de mano de obra barata, para satisfacer tales requerimientos, perdiéndose una oportunidad que otros países aprovecharon para cifrar su primera ola de expansión económica desde un tejido productivo catracho.

La influencia que tuvo el modelo ISI alentó inversiones donde ya había una huella de inversión productiva, que solo se expandió a los valles del corredor central mejor conectados al mercado, prevaleciendo el capital no local. Finalmente el modelo neoliberal cuya lógica de competitividad y libre mercado se ve reforzada y motivada a concentrarse en aquellas regiones con una buena infraestructura heredada de ciclos económicos anteriores. Esta combinación de modelos y política dejó al margen de estas dinámicas de crecimiento, a vastas regiones que por décadas han padecido de políticas excluyentes desequilibradoras de las oportunidades de desarrollo.

Si bien los modelos de desarrollo económico adoptados en Honduras, comportan una serie de supuestos económicos que en la experiencia de países europeos y asiáticos e incluso varios países de Suramérica indujeron impulsar de mejor forma sus plataformas productivas industrializadas (Kay, 2009, pp. 5-9); (Artal, 1999, pp. 6-14), es innegable que 
tales recetas fueron distorsionadas en la versión hondureña, que no supo aprovechar los períodos de bonanza de asistencia técnica de postguerra y sus préstamos blandos de cooperación estratégica, para estructurar de forma diversificada y socialmente incluyente su base productiva. Tal combinación, resultó a lo largo del período revisado, en una experiencia evidente de "mal desarrollo", cuyos resultados casi siempre generaron efectos contrarios a los prometidos, propiciando el retraso y pobreza sobre todo en las regiones internas más ignoradas de la política.

En tal sentido, puede afirmarse que no han sido las vertientes hídricas, ni la topografía irregular, tampoco los modelos económicos los principales responsables, sino los estilos y alcances de la decisión política en cada momento, lo que han marcado regiones de concentración económica y tecnológica a expensas de otras regiones también con potencial, pero llevadas a postergación. Es decir, que tales asimetrías en las cifras que ahora se manifiestan, fueron histórica y políticamente construidas al menos, en el caso hondureño.

La élite gobernante en general ignoró una realidad social que gradualmente se polarizaba hacia un abismo de brechas en el ámbito social y territorial, además que pasaron por alto otras vías de desarrollo alternativo o modalidades que se alojan a nivel de territorios del interior con características y potenciales diferenciados en la rica biodiversidad del paisaje hondureño. Como resultado se reprodujo una de las estructuras sociales y económicas más desiguales de Latinoamérica con serias implicaciones para superar desafíos que impone la globalización actual.

\section{Referencias bibliográficas}

- Aguilar, C. (2016). Dimensión territorial del potencial de desarrollo. Ecuador. Paradigma Económico, 86-90.

- Argueta, M. (junio de 1989). Bananos y política: Samuel Zemurray y la Cuyamel Fruit Company en Honduras. Tegucigalpa. : Editorial Universitaria UNAH.

- Artal, A. (1999). Modelos de Desarrollo Eonómico Latinoamericano y Shocks Externos. Universidad de Cartagena, Colombia, 1-30.

- Barquero, V. (2007). Teorías y Políticas del Desarrollo Territorial. Barcelona: Congreso Des Territorial Madrid Memoria.
- BCH, H. (2018). Estadísticas de crecimiento económco. Tegucigalpa M.D.C: BCH.

- Berdegue, J., \& F, M. (2016). Los dilemas territoriales del desarrollo en América Latina. Bogotá Colombia: Universidad de los Andes.

- Bueso, J. (1987). La crisis centroamericana y la construcción de un nuevo orden internacional en América Latina. Tegucigalpa: Edit Univers. UNAH.

- CESPAD. (2016). Centro de Estudios para la Democracia. Tegucugalpa: CESPAD.

- Criterio.hn. (noviembre de 2018). El Colapso del Modelo Económico Extractivista. págs. 1-4.

- DGL.Hn, G. (2015). Informe de Clasificación Municipal. Tegucigalpa: ANED Consultores.

- Euraque, D. (1991). El Estado Liberal y la Hipótesis la Oligarquía Ausente. Facultad de Historia Trinity College Connecticut, 1-62.

- Euraque, D. (1997). El capitalismo de San Pedro Sula y la historia política hondureña. Tegucigalpa: Guaymuras.

- Falck, M. (2000). Territorio se escribe con T, realidad y propuestas caso Honduras. Foro regional: Población, territorio y economía rural, (pág. 32). Panamá.

- Falck, M. (2006). Un país que construye territorios entre 4 corrientes. I Congreso Internacional sobre Desarrollo, (pág. 24). Madrid.

- Fortich, J. A. (2010). El panorama teórico de la economía regional y los modelos de analísis territorial. Finanzas y Política Económica. Universidad Católica de Colombia, 10-16.

- FOSDE. (2017). Economía hondureña en dirección al país de lo usado. Tegucigalpa: FOSDE.

- Gutiérrez Casas, L. (2007). Potencial de desarrollo y gestión de la política regional. Caso Chiguagua. Frontera Norte, 5-7.

- Honduras, G. d. (2009). Vision de Pais y Plan de Nacion 2010-2038. República de Honduras, 22-70.

- IICA. (2008). Situación del Desarrollo Rural y Experiencia de Honduras en Desarrollo Territorial . Tegucigalpa: Instituto Interamericano ORG. 
- INFOAGRO, S. (2009). Historia de la Agricultura Hondureña INFOAGRO. http://infoagro.sag.gob. $\mathrm{hn} /$.

- Jimenez, E. M. (2001). Evolución de los Paradigmas y Modelos Interpretativos del Desarrollo Territorial. CEPAL \#03, 1-32.

- Jimenez, E. M. (Dic. 2002). Nuevos enfoques teóricos. Evolución de las políticas regionales e impacto territorial de la globalización. ILPES CEPAL, 7-19.

- Kay, C. (2009). Persistencia de pobreza en Honduras. Nueva Sociedad, 5-9.

- Laínez, V., \& Meza, V. (1973). El enclave bananero en Honduras. Nueva Sociedad, Ariel, 2635.

- Mancini, D. G. (2015). Un territorio para el Desarrollo. PAMPA \#13.

- Meza, O. (2015). Situación de productores lácteos en Valle de Comayagua. Agronomía Cl$\mathrm{NAH}, 14-16$.

- Milanović, B. (2011). La desigualdad en el ingreso, tendencias. Finance \& Development, 2-6.

- Modrego, F., \& Berdegue, J. (2016). Los dilemas territoriales del desarrollo en América Latina. Bogotá, Colombia.: Universidad de los Andes.

- Molina Chocano, G. (1976). Estado liberal y desarrollo capitalista en Honduras. Tegucigalpa M.D.C: BCH Honduras.

- Molina Chocano, G. (1981). Centroamérica: la crisis del viejo orden. Tegucigalpa M.D.C: Guaymuras.

- Molina, C. G. (1984). Estructura productiva e historia demográfica de Honduras. Tegucigalpa: UNAH.

- Montobbio, M. (1997). La crisis centroamericana y la construcción de un nuevo orden internacional en América Latina. CIDOB, d'Afers Internacionals, 31 .

- Morris, J. (1977). Corporatism and dependent development: a Honduran case study. Latin American Research Review, 27 -68.

- Murga, F. (1985; 2 edic.). Enclave y sociedad en Honduras. Tegucigalpa: Edit. Universitaria UNAH.
- Ochoa, M. (2015). La Globalización Económica y la Desigualdad en el Desarrollo Geográfico 2001-2005. CLACSO Buenos Aires, 1- 31.

- Puente, J. M. (2003). El seguimiento y evaluación del desarrollo. Tesis doctoral, 1-32.

- Rostow, W. (1963). Las etapas del crecimiento económico; un manifiesto no comunista. DIALNET:http://www.sidalc.net/cgi-bin/wxis.exe/?।sisScript=COLPOS.xis, 26.

- Stiglitz, J. (2012). The Price of Inequality. En J. Stiglitz, The Price of Inequality (pág. resena). USA: Columbus Univ. Repositorio.

- Tellez, R. A. (2011). Dinámicas espaciales de la globalización y mutaciones regionales del desarrollo. Equidad y Desarrollo, 87-102. 